\title{
Implementation of tourism circuit concept in an android-based tourist navigation application through $\mathrm{A} *$ algorithm
}

\author{
Jonardo R. Asor ${ }^{1}$, Gene Marck B. Catedrilla ${ }^{2}$, Cris Q. De Leon ${ }^{3}$, Sharon L. Ramos ${ }^{4}$ \\ ${ }_{1,2}$ College of Computer Studies (CCS), Laguna State Polytechnic University, Laguna, Philippines \\ ${ }^{3,4}$ College of Hospitality Management and Tourism (CHMT), Laguna State Polytechnic University, Laguna, Philippines
}

\begin{tabular}{ll}
\hline Article Info & ABSTRACT \\
\cline { 2 - 3 } Article history: & $\begin{array}{l}\text { Circuit tourism allows for inclusive growth of tourism since it allows for multi- } \\
\text { site visits. Normally three or more tourist attractions are linked together in a } \\
\text { tour of the tourist's choosing. The main objective of this study is to develop an } \\
\text { Received Jan 13, } 2021\end{array}$ \\
$\begin{array}{l}\text { android-based application for searching tourist spots in Los Baños, Laguna, } \\
\text { Philippines that is also capable of recommending succeeding places to visit } \\
\text { using A* algorithm. Upon development of the application, this paper proves } \\
\text { that A* algorithm can be used to recommend another tourist spot by analyzing } \\
\text { the distance of the tourist spots near the user, and the most convenient routes } \\
\text { through which they can be reached. Based on backward and forward } \\
\text { compatibility testing, the application is operating system friendly, since it can }\end{array}$ \\
A* 31,2021 & $\begin{array}{l}\text { be used in lower versions of android. Further, it is shown in the users' } \\
\text { evaluation that the application is acceptable to the locals of Los Baños, Laguna, } \\
\text { Best path }\end{array}$ \\
GiS & $\begin{array}{l}\text { Philippines. The application also contributes to advertising other tourist spots in } \\
\text { the said municipality, specially those who were not so popular to the tourists. }\end{array}$
\end{tabular}

This is an open access article under the $\underline{C C B Y-S A}$ license.

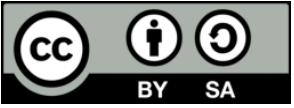

\section{Corresponding Author:}

Jonardo R. Asor

College of Computer Studies

Laguna State Polytechnic University

Malinta, Los Baños, Laguna, Philippines

Email: asor.jonardo@1spu.edu.ph

\section{INTRODUCTION}

The tourism industry significantly contributes to the economic growth of a country and is a vital source of large-scale employment and a contributor of a large chunk of a country's gross domestic product (GDP) and gross national product (GNP) [1], [2]. Tourism is also recognized as an epitome of social mobility due to its culture interaction from different parts of the world [3]. In the Philippines, the tourism industry continuously contributes to economic growth and is a powerful equity engine of the country [4]. It is a potent economic driver, accounting for 1 in every 10 jobs in the local and international employment arenas. It also translates to $11-12 \%$ of the country's GDP and GNP over the last years and has continued to bolster some of the nation's provinces' rapid economic growth. The most substantial assets of Philippine tourism are its rich and diverse indigenous cultural heritage, its natural resources and environment. However, many factors contribute to the decline of foreign tourist arrivals which includes the peace and order situation and economic crises of the country, ultimately leading to the decrease in tourist arrivals [5].

COVID-19 has affected the economic growth of countries around the world. In the January-March 2020 report of world tourism organization (UNWTO), tourism industry is the most affected of the unprecedented global health among various economic sectors. The UNWTO stressed that due to this problem, a hundred to one-twenty million direct tourism jobs are at risk because of the decline in tourist arrivals and border closure [6]. The closure of borders and the implementation of enhanced community 
quarantine in the Philippines, resulted to major loss of gross value added of 77.5 to 156.9 billion pesos or $0.8 \%$. Similarly, the sudden shutdown of many tourism business reduced 33,800 to 56,600 employment in the country [7]. Currently, there are parts of the Philippines that are already open for its local and neighboring provinces. Tourism circuit is the concept of travelling in three or more different major tourist destination that are not separated by long distances [8]. Tourism circuit is promoted in the tourism industry to ensure that all the destinations spread across the region are harnessed with quality, consistency and integrity [9], [10]. Hence, tourism circuit focuses in creating jobs for the locals and ensures environmental, socio cultural and economic outcomes for sustainability [3], [11]. The circuit approach shows an impressive result and strategic in the tourism industry. It forges a strong partnership between the government and the private sector to further enhance the tourism in the region [12]. Due to the widespread effects of the COVID-19 pandemic, it is assumed that a continuous decline of tourism arrivals is in motion. Because of this, more unconventional approaches in revitalizing the industry is encouraged.

Information technology is a well-known aide in different industry including tourism industry. It is largely used for managing destination resources, sites and attractions, tourist statistics, identifying suitable location for tourist and in inventory of tourism resources [13]. Information technology affects the tourism sector significantly. It helps the hospitality and tourism businesses to expand their market and promote efficiency among their employees [14]. In particular, geographical information systems (GIS) are used in tourism to provide digital maps, mobile mapping and digital multimedia [15]-[17].

Shortest path algorithm is widely used to solve the problem in path finding, specially when it is being applied in GIS [18], [19]. A* algorithm is well-known best-first search algorithm that is used for the recent years to solve the problem in GIS. It is famous for being the best shortest path finding algorithm because it reduces the time complexity of search and minimized the usage of physical memory and other resources [20], [21]. A* algorithm is powerful in computing the shortest path of a node to another node. Its heuristic approach makes it better than other shortest path algorithm [22]-[24]. With this, a* algorithm is a good choice to used in a mobile application that uses GIS. Assuming all the studies and literatures discussed, this paper is intended to developed an android-based application that applies the basic concept of circuit tourism to save the slowly declining growth of the industry.

\section{RESEARCH METHOD}

Different software and techniques are adapted and used in this paper to ensure the delivery of a working and significant mobile application. The study is developed adapting the linear software development method which is composed of three major phases namely of software development life cycle; data gathering and planning, design and implementation, and evaluation [25].

\subsection{Data gathering and planning}

The information on tourist spots and other leisure places in the municipality of Los Baños, Laguna in the Philippines were gathered from the Department of Tourism of Los Baños. This will be the data that will be used in the application for disseminating relevant information about the tourist spots. Further, the distance, grids and position of each tourist spots in Los Baños will be provided using MapBox application programming interface (API). Figure 1 represents the top-view of the mobile application.

The project is developed in a mobile platform since mobile devices made a major impact in the world which made it the most common device for consumer [26]. It shows that the user needs to login to the application before searching a place to go in Los Baños. Moreover, $\mathrm{A}^{*}$ algorithm is used in the application to find the best path in finding places. Likewise, the algorithm is used for recommending nearest tourist spots or leisure places to visit. $A^{*}$ algorithm was chosen to be the algorithm to use in this project since it shows an impressive result in terms of finding the best path while travelling [19].

\subsection{Design and implementation}

LakbayLB is an online mobile application for finding tourist spots and other leisure places in Los Baños, Laguna. Internet is required to access the application for real-time routing and recommendations [27]. As shown in Figure 2, it is composed of four different modules namely; suggestion, dashboard, information and videos module. Suggestion module contains the recommendation process of next spots for the user to visit. Dashboard is landing page of the application where users will login into their accounts and view the information and ratings of particular tourists' spots. Information module is where the user can view information about Los Baños, Laguna. The videos module contains some advertisements of the municipality and other agencies.

The application was developed using different technologies such as Android Studio, Java SDK, Android SDK, Firebase and Mapbox SDK. Android Studio is the main platform that was used to developed the application. Different software development kits or libraries such as Java SDK, Android SDK and 
Mapbox SDK were used to complete the features of the application. Firebase was used for the database of the mobile application. This kind of database is capable of temporary storing data while the user is in offline mode and later sync the data once connected to the internet or online. It made the best database for this project since there are some tourist spots that have poor internet signal. With the help of Firebase, the application's modules are expected to still work with poor connection and the tourists travel will not be compromised. The application was developed in android version 5.1.1 or Lollipop. Furthermore, in this phase, backward and forward testing was done for compatibility testing.

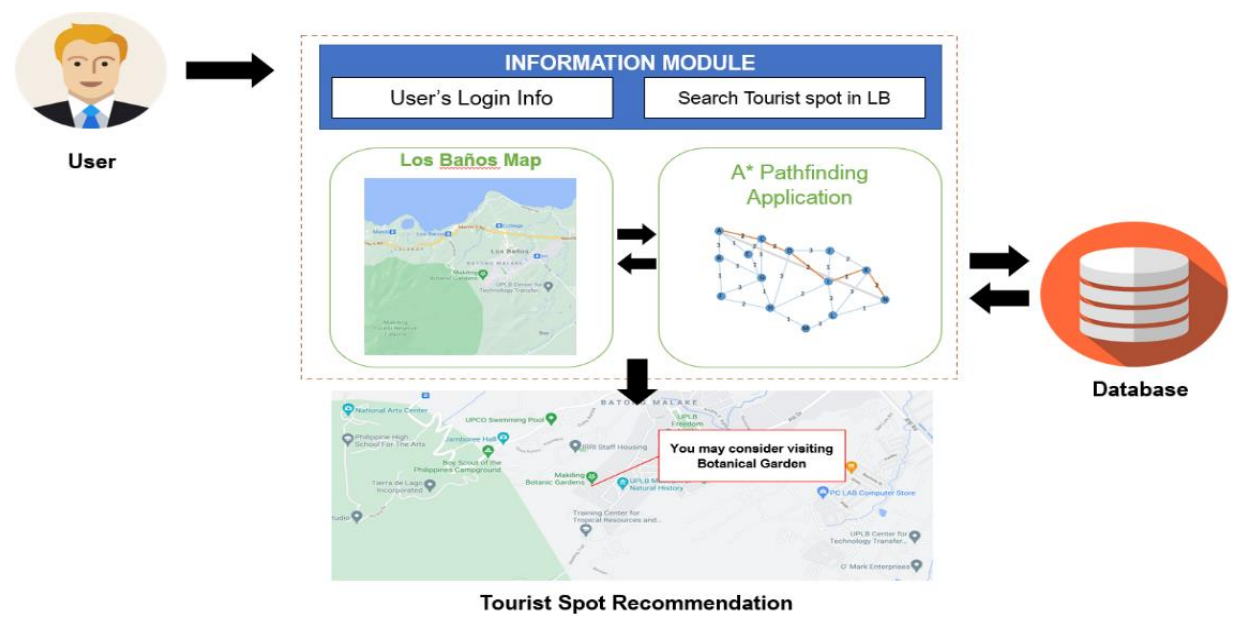

Figure 1. Concept of the LakbayLB mobile application

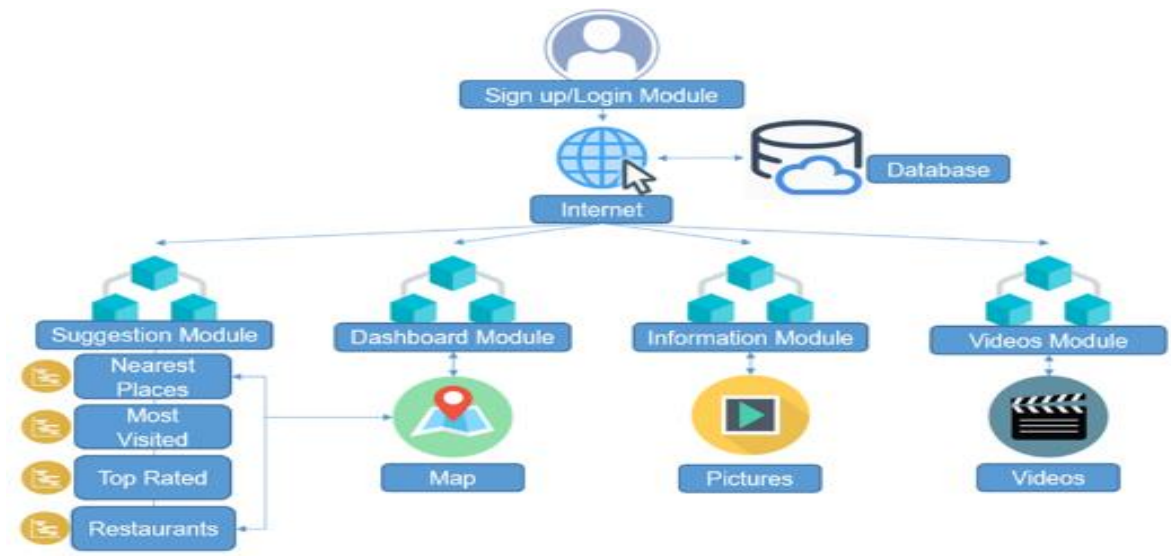

Figure 2. System architecture of LakbayLB

\subsection{Evaluation}

Since there are only a few employees in the Tourism department of Los Baños, convenience sampling method was applied in this study for evaluating the application. The respondents were five information technology experts and ten employees of days of therapy los (DOT-Los) Baños. A questionnaire containing eight categories was developed based on the eight characteristics of ISO 25010 which intended to determine the quality of the application [28]. Moreover, percentage method is used in this study to interpret the results of the evaluation.

$$
\%=\frac{f}{N} \times 100
$$

where: $\boldsymbol{f}=$ Frequency; $\boldsymbol{N}=$ Total Number of Respondents

$$
\frac{X=(S A * 4)+(A * 3)+\left(D^{*} 2\right)+\left(S D^{*} 1\right)}{T N R}
$$


where:
$X=$ Weight Mean
$\boldsymbol{A}=$ Agree
$T N R=$ Total Number of Respondents
$D=$ Disagree
$S \boldsymbol{A}=$ Strongly Agree
$S \boldsymbol{D}=$ Strongly Disagree

Table 1 shows the scale range of every rating given by the respondents in evaluating the application. The 4-point rating was adopted in this study to avoid the neural biased in evaluating the project. Moreover, 3.51 to 4 will be interpreted strongly agree, 2.51 to 3.51 is agree while 1.51 to 2.50 is disagree and 1.50 below is strongly disagree.

Table 1. Likert scale

\begin{tabular}{ccc}
\hline Rating & Scale Range & Interpretation \\
\hline 4 & $3.51-4.00$ & Strongly Agree \\
3 & $2.51-3.50$ & Agree \\
2 & $1.51-2.50$ & Disagree \\
1 & $1.00-1.50$ & Strongly Disagree \\
\hline
\end{tabular}

\section{RESULTS AND DISCUSSION}

\subsection{LakbayLB interface}

The first thing that the user will see upon accessing the application is the Figure 3 or Login page. The user needs to login his/her account first before searching particular place in Los Baños. LakbayLB's dashboard page contains a photo of searched tourist spots in Los Baños as shown in Figure 4. The user will also see the current rating of the featured spot as well as an option of giving a star to the place once visited. A short fact about the tourist spot is also provided in this page. Aside from information, the dashboard page also contains the geographical information system of the application where the route of the searched data can be viewed in real-time represented in Figure 5. The geographical information system of the application will not only show the path to follow but the approximate time of arrival as well.

With the help of Firebase database, the application will still give recommendation to the user when a signal issue occurred. Figure 6 shows how the application will show the most visited and top-rated near tourist spots to the users. This was integrated for some of the tourist spots in the municipality of Los Baños, is inside the famous mountain in the Philippines called Mt. Makiling where there are some deadspot and signal receptions are impossible.

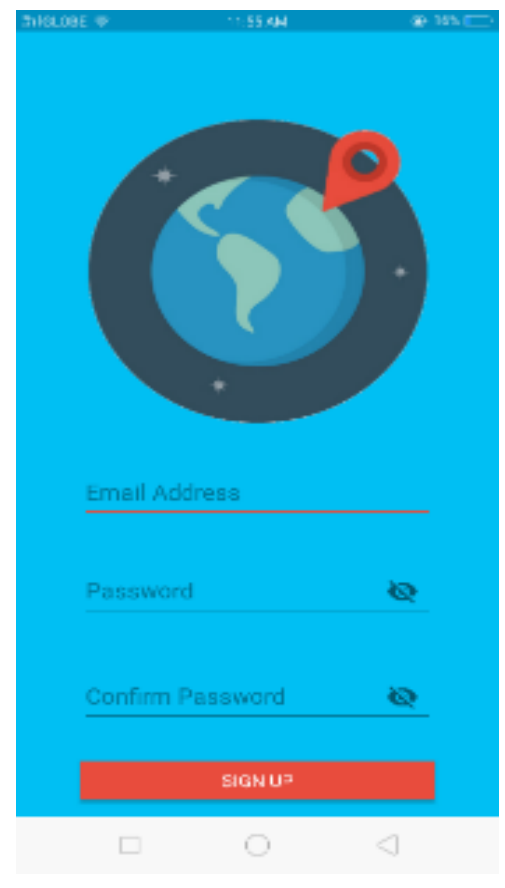

Figure 3. LakbayLB login page

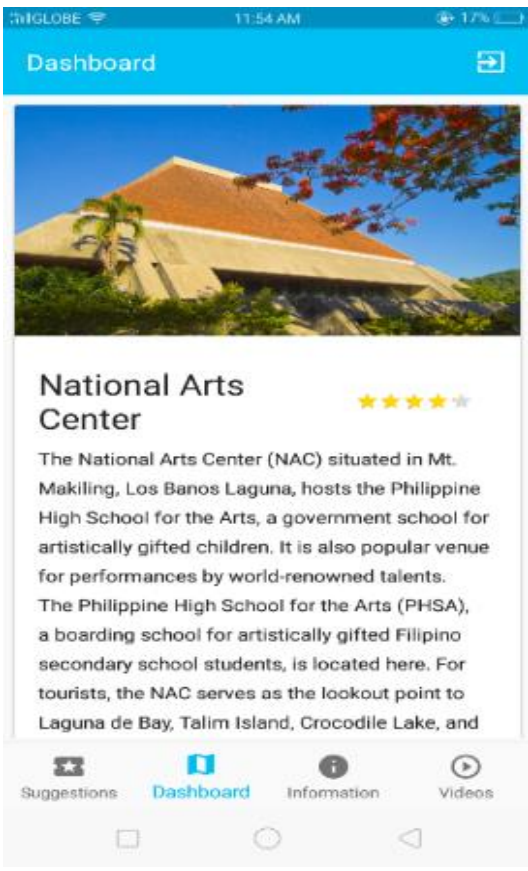

Figure 4. Dashboard of the LakbayLB 


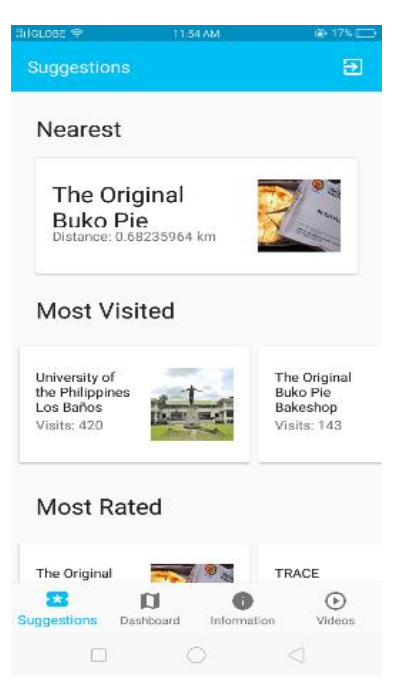

Figure 5. Suggestion module of LakbayLB

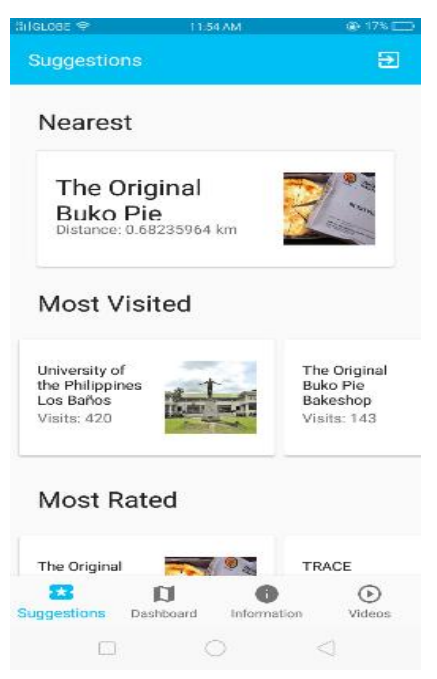

Figure 6. Suggestion module of LakbayLB

\subsection{Backward and forward compatibility testing}

The application was tested in three different lower versions of an android operating system. Since the application was developed in android Lollipop, the backward testing will be done in android KitKat, Jellybean and Ice Cream Sandwich operating system. The application successfully installed in android Jellybean and KitKat while fails in Ice Cream Sandwich were observed, as shown in Table 2.

For forward compatibility testing, the application was tested in Marshmallow, Nougat and Oreo. It was not necessary to test the application in Lollipop android version since it was developed in the said operating system. Furthermore, in Table 3, it is shown that the application can be installed and used in android operating system that is higher than Lollipop or version 5.0.

Table 2 Results of backward compatibility testing of LakbayLB

\begin{tabular}{ccccc}
\hline Android Version & Process & Expected Result & Actual Result & Remarks \\
\hline v.4.0-4.0.4 (Ice Cream Sandwich) & Install & Successfully installed & Compatibility error & Failed \\
v.4.1-4.3.1 (Jellybean) & Install & Successfully installed & Installed & Success \\
v.4.4-4.4.4 (KitKat) & Install & Successfully installed & Installed & Success \\
\hline
\end{tabular}

Table 3. Results of forward compatibility testing of LakbayLB

\begin{tabular}{ccccc}
\hline Android Version & Process & Expected Result & Actual Result & Remarks \\
\hline $6.0-6.0 .1$ (Marshmallow) & Install & Successfully installed & Installed & Success \\
v.7.0-7.1.2 (Nougat) & Install & Successfully installed & Installed & Success \\
v.8.1-8.1 (Oreo) & Install & Successfully installed & Installed & Success \\
\hline
\end{tabular}

\subsection{Evaluation of the game}

The user's evaluation is divided into eight characteristics of international organization for standardization (ISO) 25010 namely: functional suitability, performance efficiency, compatibility, usability, reliability, security, maintainability and portability. With a total numerical rating of 3.52, Table 4 shows that all the respondents strongly agreed that LakbayLB passed the ISO 25010 and is acceptable for all kind of users.

Table 4. Summary of result of LakbayLB user's evaluation

\begin{tabular}{|c|c|c|c|}
\hline Factor & Ratings & \multicolumn{2}{|c|}{ Interpretation } \\
\hline Functional Suitability & 3.44 & \multicolumn{2}{|r|}{ Agree } \\
\hline Performance Efficiency & 3.49 & \multicolumn{2}{|r|}{ Agree } \\
\hline Compatibility & 3.48 & \multicolumn{2}{|r|}{ Agree } \\
\hline Usability & 3.49 & \multicolumn{2}{|r|}{ Agree } \\
\hline Reliability & 3.41 & \multicolumn{2}{|r|}{ Agree } \\
\hline Security & 3.49 & \multicolumn{2}{|r|}{ Agree } \\
\hline Maintainability & 3.46 & \multicolumn{2}{|r|}{ Agree } \\
\hline Portability & 3.86 & \multicolumn{2}{|c|}{ Strongly Agree } \\
\hline Overall weighted mean & 3.52 & \multicolumn{2}{|c|}{ Strongly Agree } \\
\hline Rating & 3 & 2 & 1 \\
\hline Strongly Agree & Agree & Disagree & Strongly Disagree \\
\hline
\end{tabular}




\section{CONCLUSION}

Tourism circuit is the concept of tourism to give fair promotion in local tourist spots that is not long in distance with other spots. It can be a good basis for creating strategic plans to save the declining growth of tourism because of the COVID-19 pandemic. A* algorithm is a famous algorithm for finding the best path. It is proven in this paper that $\mathrm{A}^{*}$ algorithm can be used for tourist spot recommendation through distance analysis. Further, LakbayLB is operating system friendly for it can also be used in lower version of android. After the evaluation process of the application, respondents strongly agreed that the application passed the ISO standards in software development.

In this paper, it is shown that Firebase database plays a crucial role in maintaining the accessibility of the application to its user. The database features give the application the capability to run and give suggestions to the tourist despite of having problem with internet connection. Usage of local cache as alternative storage whenever the internet connection lost makes it possible to the application to search another and nearest tourist spot. Based on the findings and conclusion of this study, the usage of $\mathrm{A}^{*}$ algorithm in different software that uses path finding is recommended. Another study must be conducted in another geographical setting to further strengthen the findings of this paper. The application must be implemented by the Department of Tourism-Los Baños, to promote and strengthen its tourism industry. Lastly, the application can be used as alternative platform to advertised the not so popular tourist spots in the municipality which can saved the industry in the latter.

\section{ACKNOWLEDGEMENTS}

The author would like to thank the Laguna State Polytechnic University for its staunch support in the pursuit of scholarly research in the academe.

\section{REFERENCES}

[1] Q. M. S. M. IShaq and H. J. Padhya, "An Overview of Tourist Circuits: A Case of Rajasthan," International Journal of Management, Technology And Engineering, vol. 9, no. 1, pp. 3475-3482, 2019.

[2] P. S. Manhas, P. Kour, and A. Bhagata, "Silk route in the light of circuit tourism: An avenue of tourism internationalization," Procedia-Social and Behavioral Sciences, vol. 144, pp. 143-150, 2014, doi: 10.1016/j.sbspro.2014.07.283.

[3] V. Venugopal and S. Jamgade, "Integrated Development through Tourism Circuit: Case Study of Kannur, Kerala, India," Ramaiah University of Applied Science, vol. 6, no. 1, pp. 5-9, 2020.

[4] C. Pilapil-Añasco and J. C. Lizada, "Philippine Tourism: Evolution towards Sustainablity," in EDP Sciences, Philippines, 2014, doi: 10.1051/shsconf/20141201032.

[5] J. C. Henderson, "Tourism Development in the Philippines," Tourismos: An International Multidisciplinary Journal of Tourism, vol. 6, no. 2, pp. 159-173, 2011.

[6] W. T. Organization, "Impact Assessment of the Covid-19 Outbreak on International Tourism," UNWTO, 2020, [Online]. Available: https://www.unwto.org/impact-assessment-of-the-covid-19-outbreak-on-international-tourism

[7] N. E. D. Authority, "Addressing the Social and Economic Impact of the COVID-19 Pandemic," NEDA, Philippines, 2020.

[8] S. Chowdhary, "An overview of tourism circuits A Case study of Jammu region," International Journal of Interdisciplinary Research, vol. 1, no. 1, 2014.

[9] G. Deka and R. Pachuau, "An Overview of Tourist Circuits: A Case Study of Aizawl Area," in Academia, Aizawl, 2015.

[10] J. P. Onyango and M. Kaseje, "Tourism Planning and Development for Sustainability in Kenya's Western Tourism Circuit," American Journal of Economics, Finance and Management, vol. 1, no. 5, pp. 336-345, 2015.

[11] S. Dam, "Tourism Circuit Development in Peripheral Destinations: Case of Tripura, India," Atna-Journal of Tourism Studies, vol. 11, no. 2, pp. 1-15, 2016, doi: 10.12727/ajts.16.1.

[12] R. B. A. Alampay, M. Mena, and V. H. Villegas, "Tourism Circuit Planning for Subnational Tourism Development in the Philippines," in Managing Asian Destinations. Perspectives on Asian Tourism, Singapore, Springer, 2018, doi: 10.1007/978-981-10-8426-3_3.

[13] V. S. Jadhav and S. D. Mundhe, "Information technology in Tourism," International Journal of Computer Science and Information Technologies (IJCSIT), vol. 2, no. 6, pp. 2822-2825, 2011, doi: 10.1.1.445.7548.

[14] I. N. Wahab, "Role of Information Technology in Tourism Industry: Impact and Growth," International Journal of Innovative Research in Computer and Communication Engineering, vol. 5, no. 2, pp. 260-263, 2017

[15] V. Jovanović and A. Njeguš, "The Application of GIS and its Components in Tourism," Yugoslav Journal of Operations Research, vol. 18, no. 2, pp. 261-272, 2008, doi: 10.2298/YUJOR0802261J.

[16] T. Turk and M. U. Gumusay, "GIS Design and Application for Tourism," in XXth ISPRS Congress, Turkey, 2004.

[17] G. M. B. Catedrilla and M. A. T. Subion, "VIP READY: A Mobile Leisure Search Engine for Visually Impaired Persons Utilizing Phone Motion and Speech Recognition," in 2018 International Seminar on Research of Information Technology and Intelligent Systems (ISRITI), Yogyakarta, Indonesia, 2018, doi: 10.1109/ISRITI.2018.8864282.

[18] D. Kong, Y. Liang, X. Ma, and L. Zhang, "Improvement and Realization of Dijkstra Algorithm in GIS of Depot, in 2011 International Conference on Control, Automation and Systems Engineering (CASE), Singapore, 2011, doi: 10.1109/ICCASE.2011.5997763. 
[19] X. Z. Whang, "The Comparison of Three Algorithms in Shortest Path Issue," Journal of Physics: Conference Series, vol. 1087, 2018, pp. 1-6, doi: 10.1088/1742-6596/1087/2/022011.

[20] M. A. T. Subion and C. F. Gulay, "iSAFE: A Disaster Management Application Utilizing Georeferencing and A* Algorithm," in CIIS 2018: Proceedings of the 2018 International Conference on Computational Intelligence and Intelligent Systems, Thailand, 2018, pp. 75-79, doi: 10.1145/3293475.3293488.

[21] T. Ikeda and H. Imai, "Enhanced A* Algorithms for Multiple Alignments: Optimal Alignments for Several Sequences and k-Opt Approximate Alignments for Large Cases," Theoretical Computer Science, vol. 210, no. 2, pp. 341-374, 1999, doi: 10.1016/S0304-3975(98)00093-0.

[22] A. Goyal, P. Mogha, R. Luthra, and N. Sangwan, "Path Finding: A* or Dijkstra's?," International Journal in IT and Engineering, vol. 2, no. 1, pp. 1-15, 2014.

[23] M. A. Prasetyo, R. Latuconsina, and T. W. Purboyo, "Shortest Path Algorithms: State of the Art," International Journal of Applied Engineering Research, vol. 12, no. 23, pp. 13610-13617, 2017.

[24] L. H. O. Rios and L. Chaimowicz, "A Survey and Classification of A* based Best-First Heuristic Search Algorithms," Advances in Artificial Intelligence - SBIA 2010, pp. 253-262, 2010, doi: 10.1007/978-3-642-16138-4_26.

[25] R. Hassani and Y. El Bouzekri El Idrissi, "A Framework to succeed IT Project Management in an era of Digital Transformation," International Journal of Advanced Trends in Computer Science and Engineering, vol. 9, no. 1, pp. 630-636, 2020, doi: 10.30534/ijatcse/2020/88912020.

[26] R. Sayal, C. Subbalakhmi, and H. S. Saini, "Mobile App Accessibility for Visually Impaired," International Journal of Advanced Trends in Computer Science and Engineering, vol. 9, no. 1, pp. 182-185, 2020, doi: 10.30534/ijatcse/2020/27912020.

[27] H. S. Tantry, N. N. Murulidhar, and K. Chandrasekaran, "Impact Analysis of Legacy System Migration to the Cloud Environment: A Focused Study," International Journal of Advanced Trends in Computer Science and Engineering, vol. 9, no. 1, pp. 134-141, 2020, doi: 10.30534/ijatcse/2020/21912020.

[28] L. S. Echalar and M. A. T. Subion. "PaLife: A Mobile Application for Palay (Rice) Health Condition Classification utilizing Image Processing and Pigment Analysis towards Sustainability of Palay Production,” in 2018 International Seminar on Research of Information Technology and Intelligent Systems (ISRITI), Yogyakarta, Indonesia, 2018, doi: 10.1109/ISRITI.2018.8864286.

\section{BIOGRAPHIES OF AUTHORS}
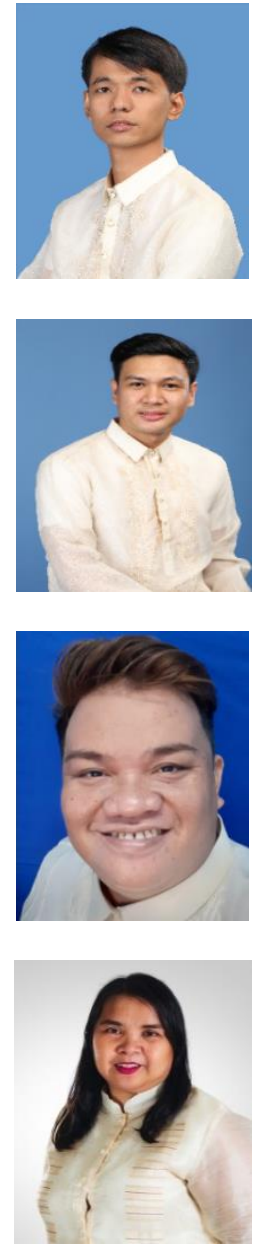

Jonardo R. Asor was born in Los Baños, Laguna, Philippines on June 12, 1990. He graduated at the Laguna State Polytechnic University-Los Baños campus with the degree bachelor of science in information technology on March 2016. Mr. Asor finished his master in information technology at the Technological Institute of the Philippines-Manila, on October 2018. He is currently working as College Instructor at the Laguna State Polytechnic University-Los Baños Campus, Malinta, Los Baños, Laguna, Philippines. His research study focuses on the optimization and usage of machine learning algorithm and knowledge discovery in databases.

Gene Marck B. Catedrilla is a graduate of Master in Information Technology at the Technological Institute of the Philippines Manila on Octobe 2018. He currently works as college instructor at the Laguna State Polytechnic University Los Baños. Mr. Catedrilla is a member of different national and international professional association related to different research discipline. His research interest is in information technology education and technology aide in person with disability.

Cris Q. De Leon was born on May 12, 1985 at Victoria, Laguna. He obtained his bachelor's degree in Hotel and Restaurant Management at the Laguna State Polytechnic University Sta. Cruz Campus in 2007, and his Master's Degree in Business Administration at the Laguna College of Business and Arts in 2015. He currently works as a University Instructor at the Laguna State Polytechnic University Los Banos Campus. He is the Editor-in-Chief of the Presidential Media Affairs Office for the University and also the Coordinator for Culture and the Arts of said University Campus. His research interest is in tourism and hospitality management.

Sharon L. Ramos is currently the associate Dean of CHMT of LSPU LB. She currently pursuing her doctor of philosophy in business administration with complete academic requirements status. She is also a member of different international association in hospitality management. Her research interest is in hospitality and tourism management. 